\title{
The moderating effect of coworkers' training participation on the influence of peer support in the transfer process
}

Coworkers' training participation

\author{
Janos Salamon
}

Doctoral School of Psychology, ELTE Eötvös Loránd University, Budapest, Hungary; Institute of Psychology, ELTE Eötvös Loránd University, Budapest, Hungary and Department of Ergonomics and Psychology, Budapest University of Technology and Economics, Budapest, Hungary

Brian D. Blume

School of Management, University of Michigan-Flint, Flint, Michigan, USA

Gábor Orosz

University of Artois, Laboratory Sherpas, Lievin, France, and

\author{
Tamás Nagy
}

Institute of Psychology, ELTE Eötvös Loránd University, Budapest, Hungary

\begin{abstract}
Purpose - The impact of the number of coworkers participating in training on transfer outcomes has largely been overlooked. This paper aims to examine whether the number of coworkers participating in training interacts with peer support (PS) to influence training motivation and transfer.
\end{abstract}

Design/methodology/approach - Data were collected using a cross-sectional survey from a sample of 688 employees working in 14 midsize and large companies. All participants were recent trainees in various open skill (e.g. leadership) training programs. Moderated mediation was used to test the hypotheses.

Findings - Motivation to transfer (MTT) mediated the relationship between PS and perceived training transfer. When more coworkers participated in the training, PS had a stronger influence on trainee MTT.

Practical implications - Organizations should consider training coworker cohorts at the same time to influence MTT and training transfer. Generally, whole-team training programs could be used to boost training transfer outcomes, although it could potentially have a negative impact on transfer if PS is low.

(C) Janos Salamon, Brian D. Blume, Gábor Orosz and Tamás Nagy. Published by Emerald Publishing Limited. This article is published under the Creative Commons Attribution (CC BY 4.0) licence. Anyone may reproduce, distribute, translate and create derivative works of this article (for both commercial and non-commercial purposes), subject to full attribution to the original publication and authors. The full terms of this licence maybe seen at http://creativecommons.org/licences/by/4.0/legalcode

This study received financial support from the Hungarian National Research, Development, and Innovation Office (Grant Numbers: PD131954, FK124225) and from the STARS scholarship (Hauts-de-France). We appreciate the support of participating companies' HR managers for their openness to cooperate in data collection and the support of those colleagues of HR departments who selected timely relevant training programs and sent recruitment emails to training participants. The authors would like to thank Kevin Ford for their constructive comments and advice.

Received 21 July 2021 Revised 24 October 2021 2 November 2021 Accepted 4 November 2021 
EJTD

47,10
Originality/value - To the best of the authors' knowledge, this was the first study to demonstrate that the number of coworkers participating in training can moderate the effect of PS on MTT and training transfer.

Keywords Peer support, Motivation to transfer, Training transfer, Coworkers' training participation, Latent moderated mediation, Training cohort

Paper type Research paper

\section{6}

\section{Introduction}

To maintain competitive advantage, organizations are compelled to train and develop employees and managers (Noe and Tews, 2012; Reio, 2020). The necessary training is often being fulfilled by providing corporate training programs. Regardless of their targeted skills, organizations need to ensure that the significant amount of dedicated resources invested into workforce training leads to a return on investment (i.e. in the form of individual and organizational benefits). For ensuring these benefits, it is essential for participants to transfer the training by applying the newfound knowledge, skills and attitudes on the job (Baldwin abd Ford, 1988; Burke and Hutchins, 2007; Ford et al., 2018). The study of the training transfer process has identified factors that are associated with successful training transfer (Ford et al., 2018; Kraiger and Ford, 2021). Among these, well-established factors, peer support has received ample research interest and its positive effect on training transfer is supported by several previous studies (Ford et al., 2018; Massenberg et al., 2015). Despite the well-known importance of PS, the potential moderating effect of how many coworkers participate in the training has largely been overlooked. Yet, this aspect of the training programs may be important in that the number of peers participating in the training could enhance the influence of PS. If this is the case, organizations could more closely consider the impact of coordinating coworker training programs. As training coworker cohorts at the same time may be relatively easy for organizations to implement, this could be a way to increase the positive effect of PS on training transfer.

This study aims to address this research gap and investigate the impact of the number of coworkers participating in training on the training transfer process. In the proposed conceptual model (Figure 1), it is assumed that the number of coworkers participating in training influences the positive relationship between PS and both motivation to transfer and training transfer. Below, we outline the hypotheses and underlying theoretical background based on the proposed model.

\section{Peer support, motivation to transfer and training transfer}

The importance of the social environment in work-related factors has been recognized by researchers of health and social psychology for decades. In their meta-analytic study,

Figure 1.

Latent moderated mediation concept model, representing the effect of PS on training transfer mediated by MTT and moderated by CTP

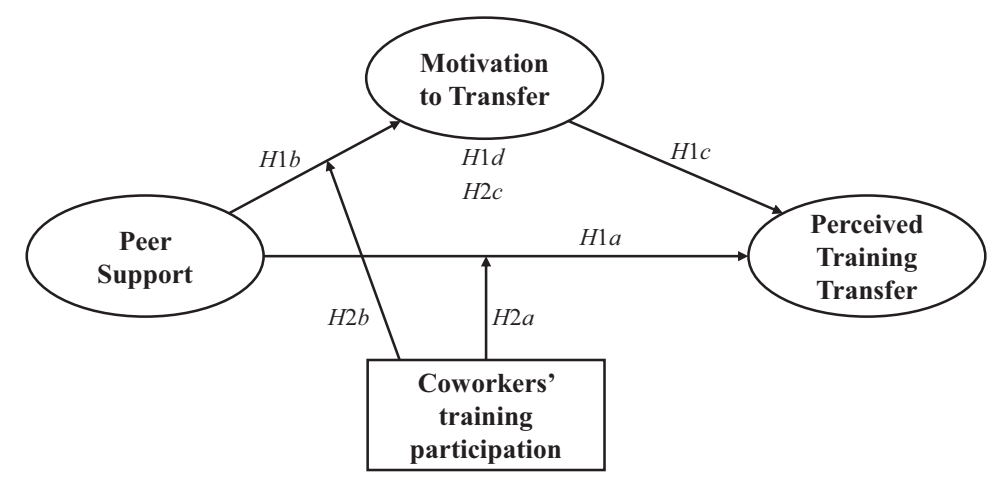


Humphrey et al. (2007) provided evidence for the positive relationship of social support with beneficial aspects of work like job-satisfaction, work motivation and performance. Social support can be defined as "the extent to which a job provides opportunities for getting assistance and advice from either supervisors or coworkers" (Humphrey et al., 2007, p. 1336). Similarly, social support is found to be an important antecedent of both MTT (Gegenfurtner et al., 2009; Richter and Kauffeld, 2020; Seyler et al., 1998) and training transfer (Blume et al., 2010; Burke and Hutchins, 2007; Ford et al., 2018). The important role of social support (e.g. peer/workgroup support, supervisor support) was identified in the early empirical work of Ford et al. (1992), Facteau et al. (1995), Holton et al. (1997) and Bates et al. (2000). Moreover, Hughes et al. (2020) in their recent meta-analysis demonstrated that social support could account for $32 \%$ of the variance in transfer. Previous studies differentiated social support types by their sources (e.g. top management, organizational, supervisory, peer and subordinate support; Facteau et al., 1995; Tracey et al., 2001) and their supportive functions (e.g. instrumental, informational, emotional and appraisal support; House, 1981). According to Hughes et al. (2020), organizational support, supervisor support and PS each have a unique contribution to training transfer. Although several studies demonstrated that support provided by different sources has an important effect on the transfer process, the current study solely examines PS with a focus on its relation to the number of coworkers participating in training.

Previous studies have proposed that social support may not directly cause the occurrence of behavior but rather functions as an environmental trigger that exerts its effect through increased motivation (Baldwin and Ford, 1988; Gegenfurtner et al., 2009). The prominent role of motivation in performing a behavior is highlighted in several models and theories of behavior change (Michie et al., 2014). Similarly, MTT - defined as the "trainees' desire to use the knowledge and skills mastered in the training program on the job" (Noe, 1986, p. 743) - has been found to be a key determinant of training transfer (Axtell et al., 1997; Baldwin and Ford, 1988; Gegenfurtner et al., 2009). Van den Bossche et al. (2010) found evidence for the partially mediating effect of MTT between the feedback provided by the work-related social network (i.e. PS) and training transfer. Similarly, Bhatti et al. (2013) and Massenberg et al. (2015) found that MTT fully mediated the effect of training interventions between PS and training transfer.

The first hypotheses serve as a foundation for this study and are directly based on these previous findings in the training transfer literature as follows:

H1a. PS is positively related to perceived training transfer.

$H 1 b$. PS is positively related to MTT.

H1c. MTT is positively related to perceived training transfer.

H1d. MTT mediates the effect of PS on perceived training transfer.

\section{Coworkers' training participation}

The training transfer literature differentiates two main categories of training programs regarding the amount of team members participating in the program. Individual training (i.e. the training of individuals) refers to the programs where training participants attend the program independently from their teams, mainly with other members of the organization. In contrast, intact-team training or whole-team training refers to the interventions where all team members participate on the same program together (Kozlowski and Ilgen, 2006; Mathieu et al., 2008). Training transfer studies support the impact of PS and MTT on training transfer for training directed at individuals (Blume et al., 2010; Burke and Hutchins, 2007; Ford et al., 2018; Gegenfurtner et al., 2009) and there is also supporting evidence for
Coworkers' training participation 
EJTD

47,10

similar patterns in whole-team training interventions (Massenberg et al., 2015). CannonBowers et al. (2003) assumed that team members can increase transfer by providing the opportunity to model and reinforce the trained behavior. They also argue that the transfer of whole-team training programs could be even more successful, as team members can provide mutual support.

While previous research shows or assumes a similar mechanism and important antecedents in both individual and team transfer processes, empirical evidence is lacking on whether there is a difference on transfer outcomes when employees participate in training alone, with some coworkers or with all coworkers. The literature suggests that training programs targeting task-relevant skills are more effective when directed to individual team members while the programs targeting knowledge, skills, attitudes necessary for effective team functioning are best to be delivered to whole-teams (Mathieu et al., 2008). The reasoning behind these assumptions is that whole-team training programs provide the opportunities for participants to integrate and jointly practice their newly acquired skills (Mathieu et al., 2008). Although the underlying logic of this assumption is clear, empirical evidence is needed.

The advantage of whole-team training over training directed at individuals can be explained by different theoretical frameworks. According to the social information processing perspective (Salancik and Pfeffer, 1978), an individual's attitude is formed by cues from their social environment beyond their own past behaviors and experiences. For example, an employee's attitude about using a new software is influenced by peer opinions shared with him at lunch. These social cues can affect attitudes in four different ways. First, overt statements and observable behavior of other people directly cues attitudes (e.g. coworker says: "I don't like this training."). Second, social influence directs the attention of individuals on certain aspects of favorable or unfavorable information, shifting their attitude toward the direction that the social cue made more salient (e.g. coworker says: "This part of the training is useful."). Third, the social environment also forms attitudes by providing interpretations of environmental cues, such as events, job characteristics and behavior (e.g. coworker says: "I can use this technique when I negotiate with my clients."). Finally, it shapes the interpretation of individual needs, highlighting the presence or absence of specific aspects that should be important to the person (e.g. coworker says: "We could not manage these sort of client complaints, we badly needed this part of the training."). These are four ways that social cues from peers in the training environment could impact trainee perceptions.

The multiple pathways of social influence (direct, attentional, interpretation and learning pathways; Grant et al., 2010; Salancik and Pfeffer, 1978) indicate that the knowledge, skills and attitudes that are targeted in a training program should be acceptable by the social environment and fit into its norms to promote application. When more coworkers participate in a training program, it is likely that the coworkers' direct experience with the training content makes their reactions more observable, and these social cues and the impact of the social environment will have a stronger impact on trainees' motivation and attitudes. For example, coworkers' reactions and behaviors would be more directly observable and more likely to lead to shared interpretation and learning pathways for the trainee. For these reasons, we expect that trainees will have a higher motivation and willingness to transfer the training when a higher percentage of those in their social environment are also receiving training.

Furthermore, a broad social consensus about the targeted skills is essential for ensuring that more people are able to provide relevant and useful feedback, which were found to be crucial for successful behavior change and training transfer (Van den Bossche et al., 2010). 
The amount of feedback and PS are also found to increase MTT (Kirwan and Birchall, 2006; Van den Bossche et al., 2010). According to Russ-Eft (2002), the information provided by the feedback allows the learner to compare their current and the desired behavior, which increases their motivation to dedicate more effort to change their behavior. Additionally, Gilpin-Jackson and Bushe (2007) highlighted the positive effect of observing the on-the-job application of the learned skills that would likely occur more frequently if coworkers participated in the training program. Based on the Social Cognitive Theory (Bandura, 1986), these observations not only increase the observers' knowledge acquisition via vicarious learning but also have a positive impact on their motivation to perform the behavior.

While the current study is the first that we are aware of to examine the effect of the different number of coworkers participating in training, based on the above reasoning and theoretical backgrounds, we propose the following regarding the moderating role of the number of coworkers participating in training:

H2a. Coworkers' training participation (CTP) moderates the relationship between PS and perceived training transfer; such that the effect of PS on perceived training transfer will be stronger when more coworkers participate in the training.

H2b. CTP moderates the relationship between PS and MTT; such that the effect of PS on MTT will be stronger when more coworkers participate in the training.

H2c. CTP moderates the MTT mediated effect of PS on perceived training transfer in such a way that the positive, mediated effect is stronger when more coworkers participate in the training program and weaker when fewer coworkers participate in the training.

\section{Method}

\section{Procedure and participants}

The study was conducted in accordance with the Declaration of Helsinki, approved by the Institutional Review Board of the Eötvös Loránd University Faculty of Education and Psychology, and is in line with the European Union's General Data Protection Regulation (2016). Data collection was conducted in 14 mid- to large-size Hungarian companies. The invitation letter to participate in the study was sent to employees who had attended a training program in the prior six months. Voluntary participation was encouraged by a lottery drawing that awarded a total of 150 small prizes, each worth about US $\$ 15$.

From a total of 864 survey respondents, the final sample included those who participated in a company-organized, open/soft-skill training program (e.g. leadership development, assertive communication, time management, sales, stress management) and who responded to the survey between 13 and 120 days after training. With the chosen timeframe, participants had at least two weeks after the classroom session to transfer the training to their job, and less than four months after training to ensure that the training was recent enough to accurately recall relevant aspects of the transfer process. In the online survey, respondents were instructed to consider the last training program in which they participated.

The final sample consisted of 688 working adults ( $48 \%$ female) who were between 22 and 67 years old $\left(M_{\text {age }}=39, S D_{\text {age }}=8.88\right)$. Regarding their organizational levels, $403(58.6 \%)$ worked at a nonmanagerial level, whereas $285(41.1 \%)$ worked at a managerial level. The 14 participating companies (workforce ranged between 500 and 15,000 employees) operate in the accounting, automotive, chemical, energy, financial, insurance, pharmaceutical, retail
Coworkers' training participation 
EJTD

47,10

and telecommunications sectors. Detailed company characteristics are shown in table S1 at the online supplementary materials on the project's open science framework (OSF) page: https://osf.io/kf9yn/?view_only=a654da486f67403f8c35a88d1f3a432c. A study that used a subset of the current database has been published (Salamon et al., 2021). However, the present study contains significantly more data, focuses on distinct research questions and includes different predictor and moderator variables.

\section{Measures}

Data collection was conducted in Hungarian. To support the potential application of the shared materials in future research, the original materials were translated into English, following a standardized translation-back translation protocol proposed by Beaton et al. (2000). The full questionnaire and related materials are available on the project's OSF page: https://osf.io/aw2kg/?view_only=a654da486f67403f8c35a88d1f3a432c. Items/responses for the first three measures listed below were provided on a seven-point Likert-scale $(1=$ Not true at all, $7=$ Completely true) as follows:

- Perceived training transfer (outcome). To assess the application of learned techniques on the job, a four-item scale from Salamon et al. (2021) was used. The items reflect a topic-independent, general behavior transferred to the job (e.g. "At my workplace, I applied the methods acquired during training."; $\alpha=$ $0.96)$.

- PS (predictor). A three-item scale was developed to measure the extent of perceived support from colleagues in the on-the-job application of the techniques learned during the training. The items were formulated based on Holton et al. (1997, p. 110) definition of PS (i.e. "the extent to which peers reinforce and support the use of learning on the job"). A sample item is "My coworkers encouraged me to use what I learned at the training." This scale had good reliability $(\alpha=0.87)$.

- MTT (mediator). A three-item scale from Salamon et al. (2021) was used to measure participants' MTT the new techniques after the training (e.g. "By the end of the training, I was determined to use the new techniques I learned at the training."). This measure has strong theoretical and empirical underpinnings (Nijman and Gelissen, 2011) and reliability was good $(\alpha=0.92)$.

- CTP (moderator). Respondents were given the following four options and indicated whether their direct colleagues (with whom they work daily) participated in the same training program: "Yes, almost all of my direct colleagues participated in this training (in the same training session)"; "Yes, some of my direct colleagues attended this training (in the same training session)."; "Yes, my colleagues participated in this training before (but in a different training group)."; "No, I was the only one to participate in this training among my direct colleagues." From these four response options a three-level scale was created by combining the two response options indicating that "some" coworkers participated in the training program. The final scale reflected three levels of CTP, including none, some and nearly all.

- Time lag (control). In line with the suggestion of Taylor et al. (2009), Salamon et al. (2021) found that participants reported less MTT when more time had passed after training. Consequently, we controlled for time lag by measuring the number of days between the end of the last training session and the response date on the survey. 
- Organizational level (control). According to Chen et al. (2006), the job type or position in the organizational hierarchy can have an effect on the perceived transferrelated variables such as MTT. Furthermore, Salamon et al. (2021) found that trainees from higher organizational levels reported higher perceived training transfer. Respondents indicated their positions and we classified these as either employee-level or manager-level.

\section{Coworkers' training participation}

\section{Statistical analysis}

Statistical analyses were performed with R 4.0.5 (R Core Team, 2020) using the lavaan package (Rosseel, 2012) for structural equation modeling (SEM). First, a preliminary measurement model was estimated, using a confirmatory factor analytic approach, to confirm the factor structure and the psychometric adequacy of the measures used in this study. For the main analyses, this measurement model was converted into the proposed predictive model (Figure 1) in which PS predicted training transfer directly and indirectly through MTT. In addition, the direct path (between PS and training transfer) and the mediation path between PS and MTT were moderated by CTP. Furthermore, the control variables time lag and organizational level were included as predictors of both training transfer and MTT. In the analysis, 1,000 bootstrap replication samples were used for estimating the $95 \%$ bias-corrected confidence intervals (CIs). For estimating the interaction between the observed moderator variable (CTP) and the latent variables (PS and MTT) in the moderated mediation model, the product indicator approach (PI; Kenny and Judd, 1984) with the double-mean-centering strategy (Lin et al., 2010) was used with SEM. Following the recommendations of Yzerbyt et al. (2018) the component approach inspired joint-significance testing of multiple parameter estimates was applied to identify the presence of the indirect effect in moderated mediation.

The models were evaluated on the basis of common goodness of fit indices and interpreted along commonly-used cut-off values (Hu and Bentler, 1999; Marsh et al., 2005) the comparative fit index (CFI; $\geq 0.95$ for excellent, $\geq 0.90$ for good), the Tucker-Lewis Index (TLI; $\geq 0.95$ for excellent, $\geq 0.90$ for good) and the root mean square error of approximation (RMSEA; $\leq 0.06$ for excellent, $\leq 0.08$ for good) with its $90 \%$ CI. Furthermore, we calculated model-based composite reliability indices $(\omega$; McDonald, 1970) which may better represent the construct, relative to Cronbach's alpha, by estimating reliability from the factor loadings and their respective measurement errors. To establish convergent validity on the construct level we calculated average variance extracted (AVE) of the constructs. Moreover, to detect any potential problems regarding discriminant validity we used Heterotrait-monotrait (HTMT) ratio analysis (Henseler et al., 2015). Finally, we estimated the variance inflation factor (VIF) for the predictor, mediator and moderator to detect potential issues of multicollinearity.

Within R 4.0.5 (R Core Team, 2020), the tidyverse package (version 1.3.0.; Wickham et al., 2019) was used for data transformation and visualization, lavaan package (version 0.6-8; Rosseel, 2012) for SEM and calculating the omega composite reliability indices, semTools package (version 0.5-4; Jorgensen et al., 2021) for conducting moderated mediation analysis. The data, a more detailed analytic plan, and the analysis code can be found on the project's OSF page: https://osf.io/aw2kg/?view_only=a654da486f67403f8c35a88d1f3a432c.

\section{Results}

Preliminary analyses

The goodness-of-fit indices showed excellent fit of the preliminary factor analytic model $\left(\chi^{2}=106.916, \mathrm{df}=46\right.$, comparative fit index $(\mathrm{CFI})=0.987$, Tucker-Lewis Index $(\mathrm{TLI})=$ 


\section{EJTD \\ 47,10}

Table 1.

Standardized parameter estimates from the preliminary model

\section{$\operatorname{PS}(\lambda) \quad \operatorname{MTT}(\lambda) \quad \operatorname{TT}(\lambda) \quad \delta$}

Peer Support (PS)

Item 1. My coworkers encouraged me to use what I learned at the training

$0.871^{* *}$

0.241

Item 2. My colleagues helped me when I had difficulties applying the new methods I had learned during training

$0.871^{\text {** }}$

Item 3. I regularly talked with my colleagues about how to best use the

methods I had learned

$0.757^{* *}$

Motivation to Transfer (MTT)

Item 1. After completing the training, I was excited to use the techniques I learned there

Item 2. By the end of the training, I felt that I would love to use what I learned immediately in my job

Item 3. By the end of the training, I was determined to use the new techniques I learned at the training

Perceived Training Transfer

Item 1. In my workplace, I used what I learned during the training

Item 2. I tried the techniques at work I had learned at the training

Item 3. At my workplace, I applied the methods acquired during training

Item 4. In my day-to-day work, I implement the knowledge that I had acquired at the training

$\omega$

AVE

$\begin{array}{llll} & 0.902^{* *} & & 0.187 \\ & 0.896^{* * *} & & 0.197 \\ & 0.869^{* * *} & & 0.245 \\ & & & \\ & & 0.920^{* *} & 0.153 \\ & & 0.922^{* *} & 0.151 \\ & & 0.952^{* *} & 0.094 \\ & & & \\ 0.873 & 0.919 & 0.893^{* *} & 0.202 \\ 0.696 & 0.791 & 0.958 & \\ & & & \end{array}$

Notes: ${ }^{* *} p<0.01 ; \lambda=$ Factor loading; $\delta=$ item uniqueness; $\omega=$ model-based omega composite reliability; $\mathrm{AVE}=$ average variance extracted

0.982, root mean square error of approximation (RMSEA) $=0.044$ [90\% CI 0.034, 0.054]). Parameter estimates (reported in Table 1) revealed well-defined and reliable factors for PS $(\lambda=0.757$ to $0.871, \omega=0.873$, AVE $=0.696)$, MTT $(\lambda=0.869$ to $0.902, \omega=0.919$, AVE $=$ $0.791)$ and training transfer $(\lambda=0.893$ to $0.952, \omega=0.958$, AVE $=0.850)$. Furthermore, the results of the preliminary analyses show that our constructs were distinct (highest HTMT ratio $=0.799$; values reported in table $\mathrm{S} 2$ at the online supplementary materials) and as VIF values did not exceed the threshold of 5 (highest VIF $=1.198$ ), multicollinearity was unlikely a problem (Hair et al., 2018; Henseler et al., 2015). Bivariate correlations from the preliminary measurement model are reported in Table 2.

\begin{tabular}{lrrrrrrr}
\hline Variables & \multicolumn{1}{c}{ M } & \multicolumn{1}{c}{ SD } & 1 & 2 & 3 & 4 & 5 \\
\hline 1. Organizational level & 0.41 & 0.49 & - & & & & \\
2. Time lag & 51.51 & 29.13 & 0.03 & - & & & \\
3. Coworkers' participation & 0.67 & 0.61 & 0.04 & 0.06 & - & & \\
4. Peer Support & 3.30 & 1.55 & $0.14^{* *}$ & 0.07 & $0.32^{* *}$ & $-{ }^{* * *}$ & - \\
5. Motivation to Transfer & 5.09 & 1.38 & 0.05 & -0.06 & 0.06 & $0.44^{* * *}$ & - \\
6. Perceived training transfer & 5.00 & 1.38 & $0.12^{* *}$ & -0.03 & $0.10^{* *}$ & $0.47^{* * *}$ & $0.79^{* *}$
\end{tabular}

Table 2.

Descriptive statistics and bivariate correlations between latent variables

Notes: $\mathrm{N}=688$, Time lag: Days elapsed between training and data collection. ${ }^{*} p<0.05 ;{ }^{* *} p<0.01$ 


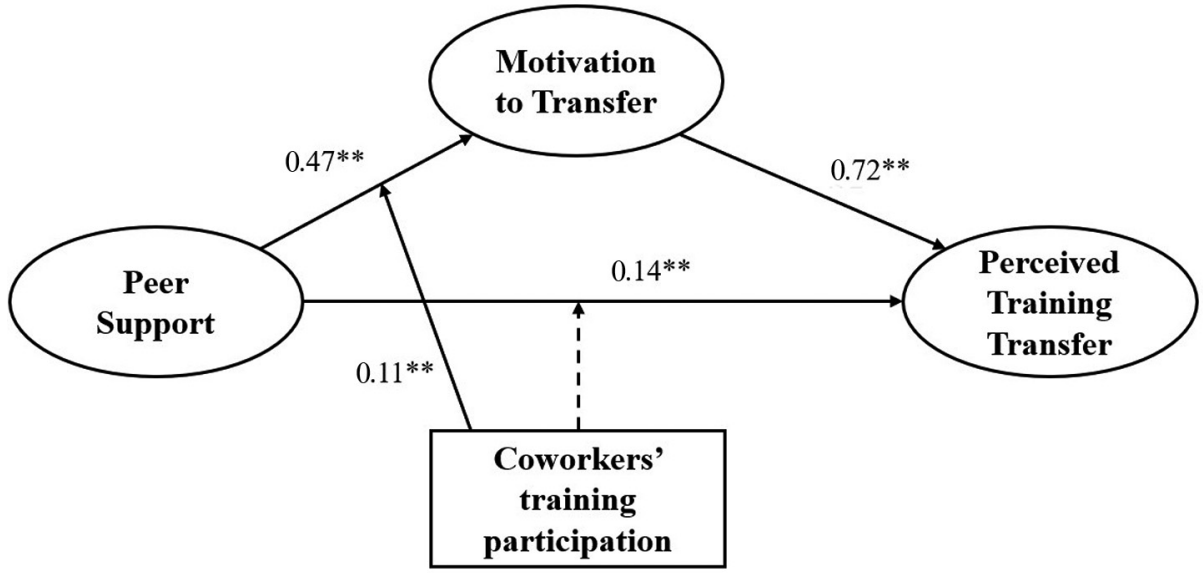

Notes: $* * p<0.01$; One-headed arrows and coefficients represent standardized regression weights. The hypothesized, nonsignificant path is drawn with a dotted line. For clarity purposes, the control variables and correlations among exogenous latent variables are excluded from the figure

\begin{tabular}{llcccrr}
\hline Hypothesis & Involved variables & $\mathrm{b}$ & $\mathrm{SE}$ & {$[95 \% \mathrm{CI}]$} & \multicolumn{1}{c}{$\beta$} & \multicolumn{1}{c}{$p$} \\
\hline$H 1 a$ & PS $\rightarrow$ TT & 0.237 & 0.049 & {$[0.134,0.324]$} & 0.14 & $<0.001$ \\
$H 1 b$ & PS $\rightarrow$ MTT & 0.535 & 0.052 & {$[0.432,0.635]$} & 0.47 & $<0.001$ \\
$H 1 c$ & MTT $\rightarrow$ TT & 1.061 & 0.090 & {$[0.902,1.247]$} & 0.72 & $<0.001$ \\
$H 1 d$ & PS $\rightarrow$ MTT $\rightarrow$ TT & 0.567 & 0.069 & {$[0.438,0.696]$} & 0.34 & $<0.001$ \\
$H 2 a$ & PS $\times$ CTP $\rightarrow$ TT & -0.012 & 0.041 & {$[-0.093,0.069]$} & -0.01 & 0.776 \\
$H 2 b$ & PS $\times$ CTP $\rightarrow$ MTT & 0.128 & 0.044 & {$[0.043,0.217]$} & 0.11 & 0.004 \\
$H 2 c$ & PS $\times$ CTP $\rightarrow$ MTT $\rightarrow$ TT & 0.136 & 0.049 & {$[0.046,0.244]$} & 0.08 & 0.006 \\
Control & Time lag $\rightarrow$ MTT & -0.104 & 0.040 & {$[-0.186,-0.029]$} & -0.09 & 0.010 \\
Control & Time lag $\rightarrow$ TT & 0.008 & 0.044 & {$[-0.076,0.100]$} & 0.01 & 0.854 \\
Control & Organizational level $\rightarrow$ MTT & -0.012 & 0.042 & {$[-0.106,0.061]$} & -0.01 & 0.777 \\
Control & Organizational level $\rightarrow$ TT & 0.105 & 0.043 & {$[0.022,0.188]$} & 0.06 & 0.016
\end{tabular}

Notes: The table represents unstandardized (b) and standardized $(\beta)$ parameter estimates with standard errors (SE) and 95\% bias-corrected bootstrapped confidence intervals $([95 \% \mathrm{CI}]) . \mathrm{N}=688$; $\mathrm{MTT}=$ motivation to transfer, TT $=$ perceived training transfer and CTP $=$ coworkers' training participation; Time lag: Days elapsed between training and data collection; PS = Peer Support
Coworkers' training participation

Figure 2 .

Latent moderated mediation statistical model, representing the effect of PS on training transfer mediated by MTT and moderated by

CTP

\section{Main analyses}

The fit indices of the latent moderated mediation model indicated an excellent fit $\left(\chi^{2}=\right.$ $229.809, \mathrm{df}=91, \mathrm{CFI}=0.982, \mathrm{TLI}=0.976, \mathrm{RMSEA}=0.047$ [90\% CI $0.040,0.055]$ ). The results of the model are shown in Figure 2 and the parameter estimates are presented in Table 3. Regarding control variables, the time lag between training and the outcome measures showed a significant negative effect on MTT $(\beta=-0.09, p=0.010)$, and no effect on training transfer $(\beta=0.01, p=0.854)$. In contrast, organizational level showed 
EJTD

47,10

24

significant association with training transfer $(\beta=0.06, p=0.016)$ and nonsignificant association with MTT $(\beta=-0.01, p=0.777)$.

In line with our expectations, $H 1 a$ and $H 1 b$ were supported. PS had a significant, direct effect both on training transfer $(\beta=0.14, p<0.001)$ and MTT $(\beta=0.47, p<0.001)$. Furthermore, in support of $H 1 c$, MTT had a positive, significant relationship with training transfer $(\beta=0.72, p<0.001)$. The joint-significance of individual parameter estimates of the indirect effects show the presence of MTT's mediating effect on the relationship between PS and training transfer $(\beta=0.34, p<0.001)$. This result supported our hypothesis $H 1 d$.

In contrast to our expectations, $H 2 a$ was not supported. The interaction of PS and CTP $(\beta=-0.01, p=0.776)$ on the relationship between PS and training transfer was not significant (i.e. the moderating effect of CTP was not supported). $H 2 b$ was supported as results indicate that the interaction between PS and CTP had a positive, significant effect on the MTT ( $\beta=0.11, p=0.004)$. The joint-significance of individual parameter estimates for

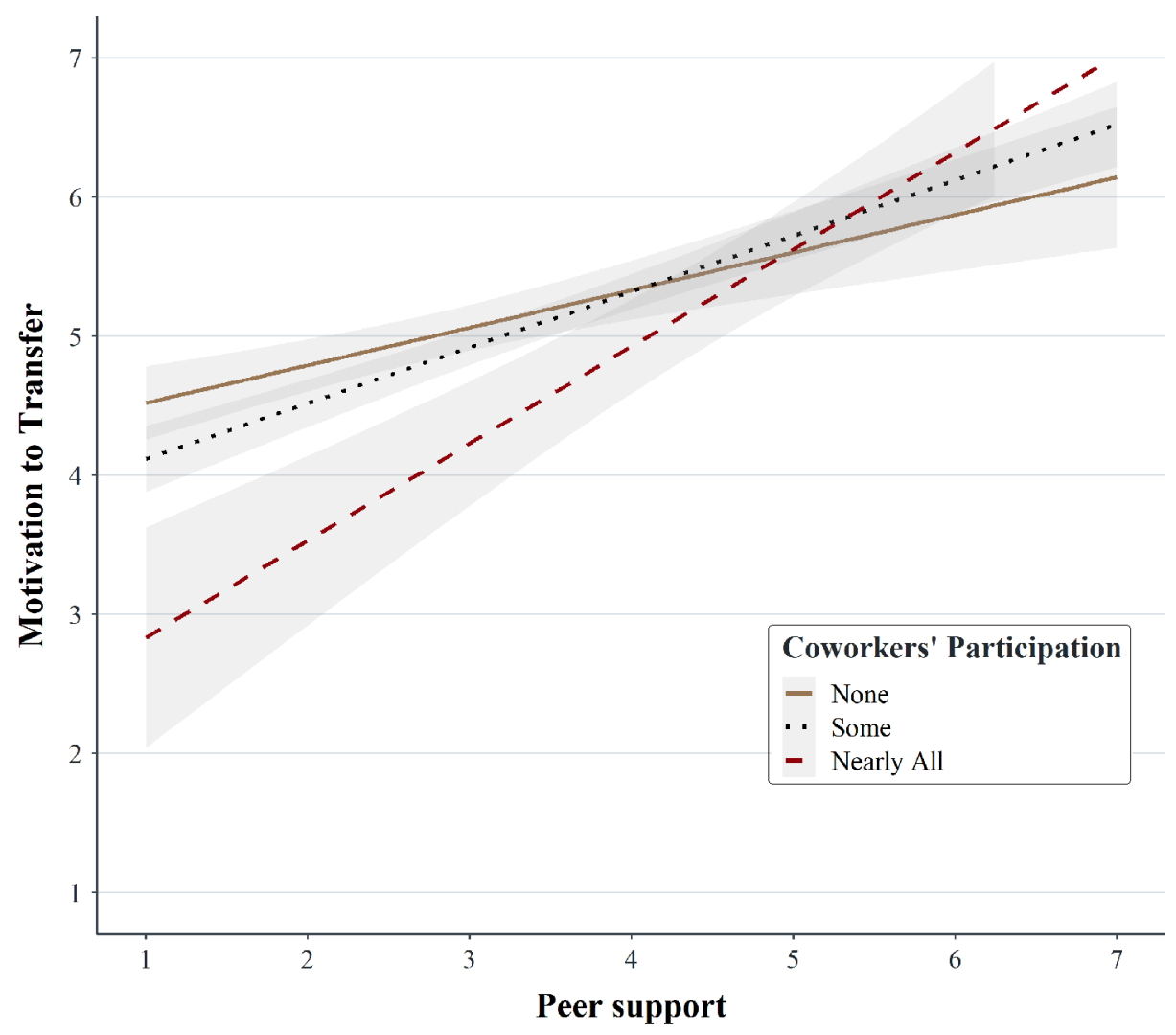

Figure 3.

Interaction effect of CTP and PS on MTT
Notes: The figure shows that PS has a stronger association with the MTT if nearly all coworkers are present in the training, compared to participating with some or no coworkers. Lines represent linear predictions and gray bands represent the standard error (SE) of predictions 
the indirect effects also provided support for the first-stage moderated mediation $(\beta=0.08$, $p=0.006)$ in $H 2 c$.

The significant interaction between PS and CTP on MTT (Figure 3) represents the importance of training cohort composition. As more coworkers participated in a training program, the peers' supportive or non-supportive behavior had more of an impact on trainee MTT.

\section{Discussion}

In the present study, we successfully replicated previous findings regarding the association between PS, MTT and training transfer. More importantly, we also found that CTP moderated the effect of PS on the transfer process. Although the number of coworkers participating in training did not moderate the direct relationship between PS and perceived training transfer, its moderation effect was present in the MTT mediated path.

The moderated mediation effect highlights the importance of the number of coworkers participating in training. This is likely related to the shared understanding and attitude about the knowledge/skill/attitude targeted in the training program. The results suggest that the positive effect of PS and MTT on training transfer can be increased by more coworkers participating in training. A higher percentage of coworker participation can increase shared understanding, the positive attitude toward the targeted behavior, the opportunity to observe the target behavior on-the-job, and can strengthen the on-the-job feedback loop. These results are in line with the assumptions of prior studies that emphasized the advantages of whole-team training programs compared to training programs directed at individuals (Mathieu et al., 2008). However, the results also show that training interventions which target nearly all coworkers could also have an undesirable effect. For example, when there is a high percentage of coworkers participating in the training, but participants do not experience support from their peers, it can negatively affect employees' MTT.

\section{Theoretical implications}

The present study aimed to investigate how the number of coworkers participating in training impacts the relationship between PS, MTT and training transfer. The findings address the previous research gap and are in line with the Social Information Processing Theory (Salancik and Pfeffer, 1978), which emphasizes the important role of the social context in attitude formation and the occurrence of a behavior. Based on this theory, a probable explanation for the moderating effect of CTP is that the higher the number of coworkers participating in a training program, the more information is available about the direct environments' attitude (acceptance or refusal) regarding the learned skills. As high coworker participation in training makes these attitudes more perceptible, it makes it easier for participants to adjust their own attitudes and behaviors to the social consensus or norm. Through direct, attentional, interpretation and learning pathways (Grant et al., 2010; Salancik and Pfeffer, 1978) these social cues influence participants' attitudes and MTT the learned skills.

Furthermore, previous studies have shown that employees who participate in a training together with more of their coworkers have a better chance to observe the learned skills that are applied on the job by their coworkers (Gilpin-Jackson and Bushe, 2007). This positive effect of observation on learning and motivation to perform the observed behavior is consistent with the Social Cognitive Theory (Bandura, 1986). Accordingly, the observation of a behavior not only increases the observers' knowledge acquisition via vicarious learning but also has a positive impact on their motivation to perform the behavior. The results of the

\section{Coworkers' training participation}


EJTD

47,10

current study show that the effect of PS (e.g. acting/leading by example) on MTT is stronger when a higher number of coworkers participate in a training program. On the one hand, this result implies that when participants receive support and observe the trained skills performed by their coworkers, they will also be motivated to apply those skills. On the other hand, participants' motivation can be diminished if they do not receive support from their coworkers and do not observe their coworkers implementing these learned skills to the job.

In the present study, $40 \%$ of the respondents participated in the training independent from the majority of their direct workgroup. This means that their coworkers likely had less knowledge or information about the topic, which could reduce their ability to provide support or motivation for training transfer (e.g. encouraging; modeling behavior; providing positive and developmental feedback). Previous research has shown that providing relevant and useful feedback is critical for successful training transfer (Van den Bossche et al., 2010). However, to provide useful and relevant feedback, a broad social consensus, common knowledge and positive attitude related to the targeted training is important. Whole-team training interventions can contribute to the learning of these shared models in the workgroup (Mathieu et al., 2005).

\section{Practical implications}

On average, respondents in this study did not experience high levels of PS. Looking more closely at the extent of PS, the results show that it is the lowest when no coworkers participate in a training, moderate when some coworkers participate and the highest level of PS is shown when nearly all coworkers participate in a training program. The fact that whole-team training programs show higher levels of PS highlights an important area for managers to focus on when they are looking for ways to enhance the transfer of training. It is likely that organizing and delivering training programs for employees who work together daily will increase the understanding, positive attitude, knowledge and skills of these teams/ coworkers. This can lead to increased PS, MTT and training transfer.

It is important to note that training programs which target nearly all coworkers without a supportive performance environment could result in worse effects on MTT than training programs directed at individuals in a similarly non-supportive environment. However, participating alone or with only a couple others from a workgroup means that the knowledge about the targeted skills and the useful feedback loop is less likely to exist when the transfer attempts occur. According to Kozlowski (2018, p. 210) whole-team training programs "are key interventions for enhancing team processes and effectiveness, but the extent to which they are used routinely by organizations (outside of the military) is limited. This is an extraordinary untapped opportunity to enhance organizational effectiveness across a broad swath of the economy." Consequently, when implementing whole-team training rather than training programs directed at individuals, it is crucial for learning and development professionals and managers to identify the barriers of PS in these programs. The lack of support may occur if peers have negative attitudes toward the training or there could be a general lack of cooperation in the team that could be improved. Alternatively, it could be that the direct social environment faces too many job demands (e.g. lack of time, extreme workload/pressure), which discourage supportive behaviors and derail trainees from transferring learned skills.

Given the above points, it seems especially important in these programs to ensure that the necessary PS will occur and to be aware of potential barriers to social support. One way to accomplish this could be to examine peer/trainee reactions toward the training via a survey to identify any negative attitudes toward training. In addition, practitioners can follow findings and suggestions in the human resource development 
literature to deliver effective training programs that are useful to trainees (Ford, 2020; Kraiger and Ford, 2021). For example, organizations should consider developing a "feedback-friendly" culture and investing in training supervisors to foster a climate in which psychological safety is high, peers support training transfer and employees proactively ask for high-quality feedback (Facteau et al., 1995; van der Rijt et al., 2012). Moreover, managers who dedicate resources to train their team should provide feedback on transfer attempts and consider whether trainees have enough dedicated time to practice and apply learned skills.

\section{Limitations and future research}

While the current study has several strengths (e.g. data collection conducted in multiple companies including multiple soft-skill training programs), there are also several limitations that should be considered in interpreting these findings. First, the current study included soft-skill training programs where workgroup support is especially important (Blume et al., 2010). Consequently, the generalizability of the findings to hard-skill training programs requires further research investigation.

Second, this study was cross-sectional with self-report measures, limiting causal interpretation of the investigated relationships. However, the implemented procedural remedies of common method variance (Podsakoff et al., 2012; Reio, 2010) incorporated into our study could alleviate the concerns of these problems. The issue of common method variance is probably the most relevant in connection with the first hypotheses $(H 1 a-H 1 d)$, where these relationships have been supported by several previous studies (Blume et al., 2010; Ford et al., 2018). In addition, self-report data collection is more acceptable regarding variables that measure respondents' internal states, such as the perceived support and MTT variables in this study (Spector, 2019). Furthermore, the other hypotheses tested interaction effects, and research suggests that although interaction effects can be deflated by method bias, they are unlikely to be artifacts of it (Podsakoff et al., 2012; Siemsen et al., 2010). Nevertheless, replication of the study in conditions where other-reports of transfer are analyzed and a time lag between surveys is applied would provide further evidence.

Third, the CTP moderator variable had unequal subgroup sample sizes. In total, $40 \%$ of the respondents were the only one in their direct workgroup to participate in the training program, $52 \%$ of the respondents had some coworkers who also participated in the training program, and only $8 \%$ of the respondents indicated that nearly all their coworkers participated in the training program. As the unequal sample sizes can significantly decrease the power to detect the effect of a moderator variable (Aguinis, 1995), it could be a potential reason for the nonsignificant effect of the number of coworkers participating in training on the relationship between PS and training transfer. Consequently, to handle this issue, future research that investigates similar relationships should aim for more equal subgroup sample sizes (Aguinis, 1995).

A promising direction for future research would be to investigate the individual characteristics and contextual factors that may moderate the effect of the number of CTP on transfer outcomes. Self-monitoring is an example of a trainee characteristic that could moderate the influence of CTP in the transfer process. The extent of self-monitoring was found to be an important moderator of social adjustment. High self-monitoring individuals are more sensitive to and tend to follow social norms, whereas low self-monitors are more likely to follow their internal attitudes and beliefs to guide their behaviors (Snyder, 1974; Burkhardt, 1994). Another important variable in connection with the effect of social cues is
Coworkers' training participation 
EJTD

47,10

related to self-identity variables like organizational or workgroup identification (Chen et al., 2013).

An additional direction for future research could be to explore the percentage of coworkers as training participants required to have high PS. For example, is it necessary for $100 \%$ of coworkers to participate or could $50 \%$ or $75 \%$ of a team training participation still provide a positive environment of PS to facilitate trainee motivation and transfer? A related question is whether the percentage of coworkers (i.e. the ratio of the social environment affected by the training initiative) or a specified "high" number of coworkers has more impact on the effect of PS in the transfer process. Furthermore, while the current study assumed that each coworker would have the same effect on a trainee, future research could consider investigating how certain peers may have a larger influence on a group (Chen et al., 2013). For example, these could consider the impact of a coworker's network position (social network approach) or the different quality of relationships, such as their strength and influence (relational approach). It can be assumed that the following statement is applicable in the context of training transfer: "those who are socially more important will exert a greater influence on the focal employee than others" (Chen et al., 2013, p. 1621). Furthermore, future research would be necessary to provide further information regarding the reasons for the presence or absence of PS in a work environment.

\section{Conclusion}

The present study unveiled an important but relatively neglected aspect of training programs. In line with theory that emphasizes the impact of the social context on individuals' attitudes and learning, the results show that when more coworkers from a team participate in a training, PS has a stronger influence on MTT. Therefore, organizations should consider how the decision of when to train coworkers may influence transfer outcomes; and they should consider training cohorts at the same time.

\section{References}

Aguinis, H. (1995), "Statistical power problems with moderated multiple regression in management research", Journal of Management, Vol. 21 No. 6, pp. 1141-1158, available at: https://doi.org/ 10.1016/0149-2063(95)90026-8

Axtell, C.M., Maitlis, S. and Yearta, S.K. (1997), "Predicting immediate and longer-term transfer of training", Personnel Review, Vol. 26 No. 3, pp. 201-213, available at: https://doi.org/10.1108/ 00483489710161413

Baldwin, T.T. and Ford, J.K. (1988), "Transfer of training: a review and directions for future research", Personnel Psychology, Vol. 41 No. 1, pp. 63-105, available at: https://doi.org/10.1111/j.17446570.1988.tb00632.x

Bandura, A. (1986), Social Foundations of Thought and Action: A Social Cognitive Theory, PrenticeHall, Inc, Englewood Cliffs, NJ.

Bates, R.A., Holton, E.F., III, Seyler, D.L. and Carvalho, M.A. (2000), "The role of interpersonal factors in the application of computer-based training in an industrial setting", Human Resource Development International, Vol. 3 No. 1, pp. 19-42, available at: https://oi.org/10.1080/136788600361920

Beaton, D.E., Bombardier, C., Guillemin, F. and Ferraz, M.B. (2000), "Guidelines for the process of crosscultural adaptation of self-report measures”, Spine, Vol. 25 No. 24, pp. 3186-3191, available at: https://doi.org/10.1097/00007632-200012150-00014 
Bhatti, M.A., Battour, M.M., Sundram, V.P.K. and Othman, A.A. (2013), "Transfer of training: does it truly happen? An examination of support, instrumentality, retention and learner readiness on the transfer motivation and transfer of training", European Journal of Training and Development, Vol. 37 No. 3, pp. 273-297, available at: https://doi.org/10.1108/03090591311312741

\section{Coworkers' training participation}

Blume, B.D., Ford, J.K., Baldwin, T.T. and Huang, J.L. (2010), "Transfer of training: a meta-analytic review", Journal of Management, Vol. 36 No. 4, pp. 1065-1105, available at: https://doi.org/ $10.1177 / 0149206309352880$

Burke, L.A. and Hutchins, H.M. (2007), "Training transfer: an integrative literature review”, Human Resource Development Review, Vol. 6 No. 3, pp. 263-296, available at: https://doi.org/10.1177/ 1534484307303035

Burkhardt, M.E. (1994), "Social interaction effects following a technological change: a longitudinal investigation", Academy of Management Journal, Vol. 37 No. 4, pp. 869-898, available at: https:// doi.org/10.5465/256603

Cannon-Bowers, J.A., Salas, E. and Milham, L.M. (2003), "The transfer of team training: recommendations for practice", in Holton, E. F. III and Baldwin, T.T. (Eds), Improving Learning Transfer in Organizations, Jossey-Bass, San Francisco, CA, pp. 195-223.

Chen, H.-C., Holton Iii, E.F. and Bates, R.A. (2006), "Situational and demographic influences on transfer system characteristics in organizations", Performance Improvement Quarterly, Vol. 19 No. 3, pp. 7-26, available at: https://doi.org/10.1111/j.1937-8327.2006.tb00375.x

Chen, Z., Takeuchi, R. and Shum, C. (2013), "A social information processing perspective of coworker influence on a focal employee”, Organization Science, Vol. 24 No. 6, pp. 1618-1639, available at: https://doi.org/10.1287/orsc.2013.0820

Facteau, J.D., Dobbins, G.H., Russell, J.E., Ladd, R.T. and Kudisch, J.D. (1995), “The influence of general perceptions of the training environment on pretraining motivation and perceived training transfer", Journal of Management, Vol. 21 No. 1, pp. 1-25, available at: https://doi.org/10.1016/ 0149-2063(95)90031-4

Ford, J.K. (2020), Learning in Organizations: An Evidence-Based Approach, Routledge, New York, NY.

Ford, J.K., Baldwin, T.T. and Prasad, J. (2018), "Transfer of training: the known and the unknown”, Annual Review of Organizational Psychology and Organizational Behavior, Vol. 5 No. 1, pp. 201-225, available at: https://doi.org/10.1146/annurev-orgpsych-032117-104443

Ford, J.K., Quiñones, M.A., Sego, D.J. and Sorra, J.S. (1992), "Factors affecting the opportunity to perform trained tasks on the job”, Personnel Psychology, Vol. 45 No. 3, pp. 511-527, available at: https://doi.org/10.1111/j.1744-6570.1992.tb00858.x

Gegenfurtner, A., Veermans, K., Festner, D. and Gruber, H. (2009), "Integrative literature review: motivation to transfer training: an integrative literature review", Human Resource Development Review, Vol. 8 No. 3, pp. 403-423, available at: https://doi.org/10.1177/ 1534484309335970

Gilpin-Jackson, Y. and Bushe, G.R. (2007), "Leadership development training transfer: a case study of post-training determinants", Journal of Management Development, Vol. 26 No. 10, pp. 980-1004, available at: https://doi.org/10.1108/02621710710833423

Grant, A.M., Fried, Y. and Juillerat, T. (2010), "Work matters: job design in classic and contemporary perspectives", In Zedeck, S. (Ed.), APA Handbook of Industrial and Organizational Psychology, Vol. 1, American Psychological Association, Washington, DC, pp. 417-453.

Hair, J.F., Black, W.C., Babin, B.J. and Anderson, R.E. (2018), Multivariate Data Analysis, 8th ed., Cengage, Andover, Hampshire.

Henseler, J., Ringle, C.M. and Sarstedt, M. (2015), "A new criterion for assessing discriminant validity in variance-based structural equation modeling”, Journal of the Academy of Marketing Science, Vol. 43 No. 1, pp. 115-135. 
EJTD

47,10

Holton, I.I.I., E.F., Bates, R.A., Seyler, D.L. and Carvalho, M.B. (1997), “Toward construct validation of a transfer climate instrument", Human Resource Development Quarterly, Vol. 8 No. 2, pp. 95-113, available at: https://doi.org/10.1002/hrdq.3920080203

House, J. (1981), Work Stress and Social Support, Addison-Wesley, Reading, MA.

Hu, L. and Bentler, P., M. (1999), "Cutoff criteria for fit indexes in covariance structure analysis: conventional criteria versus new alternatives", Structural Equation Modeling: A Multidisciplinary Journal, Vol. 6 No. 1, pp. 1-55, available at: https://doi.org/10.1080/10705519909540118

Hughes, A.M., Zajac, S., Woods, A.L. and Salas, E. (2020), "The role of work environment in training sustainment: a meta-analysis", Human Factors: The Journal of the Human Factors and Ergonomics Society, Vol. 62 No. 1, pp. 166-183, available at: https://doi.org/10.1177/0018720819845988

Humphrey, S.E., Nahrgang, J.D. and Morgeson, F.P. (2007), "Integrating motivational, social, and contextual work design features: a meta-analytic summary and theoretical extension of the work design literature", Journal of Applied Psychology, Vol. 92 No. 5, p. 1332, available at: https://doi. org/10.1037/0021-9010.92.5.1332

Jorgensen, T.D., Pornprasertmanit, S., Schoemann, A.M. and Rosseel, Y. (2021), "semTools: Useful tools for structural equation modeling [computer software manual]", available at: https://CRAN.Rproject.org/package $=$ semTools

Kenny, D.A. and Judd, C.M. (1984), "Estimating the nonlinear and interactive effects of latent variables", Psychological Bulletin, Vol. 96 No. 1, p. 201, available at: https://doi.org/10.1037/00332909.96.1.201

Kirwan, C. and Birchall, D. (2006), "Transfer of learning from management development programmes: Testing the holton model", International Journal of Training and Development, Vol. 10 No. 4, pp. 252-268, available at: https://doi.org/10.1111/j.1468-2419.2006.00259.x

Kozlowski, S.W. (2018), "Enhancing the effectiveness of work groups and teams: a reflection", Perspectives on Psychological Science, Vol. 13 No. 2, pp. 205-212, available at: https://doi.org/ $10.1177 / 1745691617697078$

Kozlowski, S.W. and Ilgen, D.R. (2006), "Enhancing the effectiveness of work groups and teams", Psychological Science in the Public Interest, Vol. 7 No. 3, pp. 77-124, available at: https://doi.org/ 10.1111/j.1529-1006.2006.00030.x

Kraiger, K. and Ford, J.K. (2021), "The science of workplace instruction: learning and development applied to work", Annual Review of Organizational Psychology and Organizational Behavior, Vol. 8 No. 1, pp. 45-72, available at: https://doi.org/10.1146/annurev-orgpsych-012420-060109

Lin, G.-C., Wen, Z., Marsh, H.W. and Lin, H.-S. (2010), "Structural equation models of latent interactions: clarification of orthogonalizing and double-mean-centering strategies", Structural Equation Modeling: A Multidisciplinary Journal, Vol. 17 No. 3, pp. 374-391, available at: https://doi.org/ 10.1080/10705511.2010.488999

McDonald, R.P. (1970), "The theoretical foundations of principal factor analysis, canonical factor analysis, and alpha factor analysis", British Journal of Mathematical and Statistical Psychology, Vol. 23 No. 1, pp. 1-21, available at: https://doi.org/10.1111/j.2044-8317.1970.tb00432.x

Marsh, H.W., Hau, K.-T. and Grayson, D. (2005), "Goodness of fit in structural equation models", in McArdle, J.J. and Maydeu-Olivares, A. (Eds), Multivariate Applications Book Series. Contemporary Psychometrics: A Festschrift for Roderick, in McDonald, P. (Eds), Lawrence Erlbaum Associates Publishers, pp. 275-340.

Massenberg, A.C., Spurk, D. and Kauffeld, S. (2015), "Social support at the workplace, motivation to transfer and training transfer: a multilevel indirect effects model", International Journal of Training and Development, Vol. 19 No. 3, pp. 161-178, available at: https://doi.org/10.1111/ ijtd.12054

Mathieu, J., Maynard, M.T., Rapp, T. and Gilson, L. (2008), "Team effectiveness 1997-2007: a review of recent advancements and a glimpse into the future", Journal of Management, Vol. 34 No. 3, pp. 410-476, available at: https://doi.org/10.1177/0149206308316061 
Mathieu, J.E., Heffner, T.S., Goodwin, G.F., Cannon, -Bowers, J.A. and Salas, E. (2005), "Scaling the quality of teammates' mental models: equifinality and normative comparisons", Journal of Organizational Behavior, Vol. 26 No. 1, pp. 37-56, available at: https://doi.org/10.1002/job.296

Michie, S.F., West, R., Campbell, R., Brown, J. and Gainforth, H. (2014), ABC of Behaviour Change Theories, Silverback publishing.

Nijman, D.-J. and Gelissen, J. (2011), "Direct and indirect effects of supervisor support on transfer of training", in Poell, R.F. and van Woerkom, M. (Eds), Supporting Workplace Learning, Springer, pp. 89-106, available at: https://doi.org/10.1007/978-90-481-9109-3_6

Noe, R.A. (1986), "Trainees' attributes and attitudes: neglected influences on training effectiveness", Academy of Management Review, Vol. 11 No. 4, pp. 736-749, available at: https://doi.org/10.5465/ amr.1986.4283922

Noe, R.A. and Tews, M.J. (2012), "Realigning training and development research to contribute to the psychology of competitive advantage", Industrial and Organizational Psychology, Vol. 5 No. 1, pp. 101-104, available at: https://doi.org/10.1111/j.17549434.2011.01412.x

Podsakoff, P.M., MacKenzie, S.B. and Podsakoff, N.P. (2012), "Sources of method bias in social science research and recommendations on how to control it", Annual Review of Psychology, Vol. 63 No. 1, pp. 539-569, available at: https://doi.org/10.1146/annurev-psych-120710100452

R Core Team (2020), $R$ : A language and environment for statistical computing. $R$ Foundation for Statistical Computing, Vienna, available at: www.R-project.org/

Regulation, G.D.P. (2016), "Regulation (EU) 2016/679 of the european parliament and of the council of 27 april 2016 on the protection of natural persons with regard to the processing of personal data and on the free movement of such data, and repealing directive 95/46", Official Journal of the European Union, Vol. 59, pp. 1-88.

Reio, T.G. Jr (2010), "The threat of common method variance bias to theory building", Human Resource Development Review, Vol. 9 No. 4, pp. 405-411, available at: https://doi.org/ $10.1177 / 1534484310380331$

Reio, T.G. Jr (2020), “Competitive advantage and HRD”, Human Resource Development Quarterly, Vol. 31 No. 4, pp. 353-354, available at: https://doi.org/10.1002/hrdq.21413

Richter, S. and Kauffeld, S. (2020), "Beyond supervisors' support: influencing (international) technical training transfer", European Journal of Training and Development, Vol. 44 Nos 4/5, pp. 391-403, available at: https://doi.org/10.1108/EJTD-08-2019-0141

Rosseel, Y. (2012), "Lavaan: an R package for structural equation modeling", Journal of Statistical Software, Vol. 48 No. 2, available at: https://doi.org/10.18637/jss.v048.i02

Russ-Eft, D. (2002), "A typology of training design and work environment factors affecting workplace learning and transfer", Human Resource Development Review, Vol. 1 No. 1, pp. 45-65, available at: https://doi.org/10.1177/1534484302011003

Salamon, J., Blume, B.D., Orosz, G. and Nagy, T. (2021), "The interplay between the level of voluntary participation and supervisor support", Human Resource Development Quarterly, Vol. 32 No. 4, pp. 459-481, available at: https://doi.org/10.1002/hrdq.21428

Salancik, G.R. and Pfeffer, J. (1978), "A social information processing approach to job attitudes and task design”, Administrative Science Quarterly, Vol. 23 No. 2, pp. 224-253, doi: 10.2307/ 2392563.

Seyler, D.L., Holton Iii, E.F., Bates, R.A., Burnett, M.F. and Carvalho, M.A. (1998), "Factors affecting motivation to transfer training”, International Journal of Training and Development, Vol. 2 No. 1, pp. 16-16, available at: https://doi.org/10.1111/1468-2419.00031 
EJTD

47,10

Siemsen, E., Roth, A. and Oliveira, P. (2010), "Common method bias in regression models with linear, quadratic, and interaction effects”, Organizational Research Methods, Vol. 13 No. 3, pp. 456-476, available at: https://doi.org/10.1177/1094428109351241

Snyder, M. (1974), "Self-monitoring of expressive behavior", Journal of Personality and Social Psychology, Vol. 30 No. 4, p. 526, available at: https://doi.org/10.1037/h0037039

Spector, P.E. (2019), "Do not cross me: optimizing the use of cross-sectional designs", Journal of Business and Psychology, Vol. 34 No. 2, pp. 125-137, available at: https://doi.org/10.1007/s10869018-09613-8

Taylor, P.J., Russ-Eft, D.F. and Taylor, H. (2009), "Transfer of management training from alternative perspectives", Journal of Applied Psychology, Vol. 94 No. 1, pp. 104-121, available at: https://doi. org/10.1037/a0013006

Tracey, J.B., Hinkin, T.R., Tannenbaum, S. and Mathieu, J.E. (2001), "The influence of individual characteristics and the work environment on varying levels of training outcomes", Human Resource Development Quarterly, Vol. 12 No. 1, pp. 5-23, available at: https://doi.org/10.1002/ 1532-1096(200101/02)12:1<5::AID-HRDQ2>3.0.CO;2-J

Van den Bossche, P., Segers, M. and Jansen, N. (2010), "Transfer of training: the role of feedback in supportive social networks", International Journal of Training and Development, Vol. 14 No. 2 , pp. 81-94, available at: https://doi.org/10.1111/j.1468-2419.2010.00343.x

Van der Rijt, J., van de Wiel, M.W., Van den Bossche, P., Segers, M.S. and Gijselaers, W.H. (2012), "Contextual antecedents of informal feedback in the workplace", Human Resource Development Quarterly, Vol. 23 No. 2, pp. 233-257, available at: https://doi.org/10.1002/hrdq.21129

Wickham, H., Averick, M., Bryan, J., Chang, W., McGowan, L., François, R., Grolemund, G., Hayes, A., Henry, L., Hester, J., Kuhn, M., Pedersen, T., Miller, E., Bache, S., Müller, K., Ooms, J., Robinson, D., Seidel, D., Spinu, V., . . Y Yutani, H. (2019), "Welcome to the tidyverse", Journal of Open Source Software, Vol. 4 No. 43, p. 1686, available at: https://doi.org/10.21105/joss.01686

Yzerbyt, V., Muller, D., Batailler, C. and Judd, C.M. (2018), "New recommendations for testing indirect effects in mediational models: the need to report and test component paths", Journal of Personality and Social Psychology, Vol. 115 No. 6, pp. 929-943, available at: http://dx.doi.org/ 10.1037/pspa0000132

\section{Appendix. Detailed analytic plan}

\section{Statistical analysis}

Statistical analyses were performed with R 4.0.5 (R Core Team, 2020) using the robust maximum likelihood (MLR) estimator, which provides tests of model fit and standard errors that are robust to non-normality. First, a preliminary measurement model was estimated using a confirmatory factor analytic approach to confirm the factor structure and the psychometric adequacy of the measures used in this study. In this preliminary model, scale items loaded on their corresponding latent factors, and the factors were freely allowed to correlate with one another. Relying on fully latent variables also allowed us to reduce the biasing effect of item-level measurement error, in turn obtaining more accurate parameter estimates (Cheung et al., 2017; Cortina et al., 2021; Finkel, 1995).

For the main analyses, this measurement model was converted into the proposed predictive model (Figure 1) in which peer support predicted training transfer directly and indirectly through motivation to transfer. In addition to that, in the proposed predictive model, the direct path (between peer support and training transfer), and the mediation path between peer support and motivation to transfer were moderated by coworkers' training participation. Furthermore, both 
training transfer and motivation to transfer were also predicted by time lag and organizational level. In the analysis, 1,000 bootstrap replication samples were used for estimating the $95 \%$ biascorrected confidence intervals (CIs). These were computed with the maximum likelihood estimator, as bootstrapping is not available with the MLR estimator. For estimating the interaction between the observed moderator variable (coworkers' training participation) and the latent variables (peer support and motivation to transfer) in the moderated mediation model, the product indicator approach (PI; Kenny and Judd, 1984) with the double-mean-centering strategy (Lin et al., 2010) was used with structural equation modeling (SEM). This approach is a well-performing alternative to latent moderated structural equations (LMS, which are only available in Mplus; Muthén and Muthén, 2012). PI is also robust to heteroskedasticity (Kolbe et al., 2020), which obtains similar power, but lower Type 1 error rates than LMS (Kolbe and Jorgensen, 2019), can be implemented into any software program, and provides more traditional SEM fit indices that are not available when using LMS in Mplus (Kolbe and Jorgensen, 2018). Following the recommendations of Yzerbyt et al. (2018), the component approach inspired joint-significance testing of multiple parameter estimates was applied to identify the presence of the indirect effect in moderated mediation.

The models were evaluated on the basis of common goodness-of-fit indices and interpreted along commonly-used cut-off values (Hu and Bentler, 1999; Marsh et al., 2005) the comparative fit index (CFI; $\geq 0.95$ for excellent, $\geq 0.90$ for good), the Tucker-Lewis Index (TLI; $\geq 0.95$ for excellent, $\geq 0.90$ for good) and the root mean square error of approximation (RMSEA; $\leq 0.06$ for excellent, $\leq 0.08$ for good) with its $90 \%$ CI. In the preliminary measurement model, the definition of the factors was interpreted based on the magnitude of their factor loadings. Following the recommendation of Morin et al. (2020) factor loadings greater than 500 were accepted as satisfactory. This simple rule is generally in line with the more detailed guidelines of Comrey and Lee (1992) who suggested to interpret factor loadings as excellent above 0.71, very good between 0.63 and 0.70 , good between 0.55 and 0.62 , fair between 0.44 and 0.33 and poor below 0.32 .

Furthermore, we calculated model-based composite reliability indices ( $\omega$; McDonald, 1970; Morin et al., 2020) as $\omega=\left(\Sigma\left|\lambda_{\mathrm{i}}\right|\right)^{2} /\left(\left[\Sigma\left|\mathbb{\Delta}_{\mathrm{i}}\right|\right]^{2}+\Sigma \delta_{\mathrm{ii}}\right)$ where $\mathbb{\Xi}_{\mathrm{i}}$ represents the factor loadings, and $\mathbb{\mathrm { i }}_{\mathrm{ii}}$ indicates the error variances. Its advantage is that it may better represent the construct, relative to Cronbach's alpha, by estimating reliability from the factor loadings $\left(\lambda_{\mathrm{i}}\right)$ and their respective measurement errors $\left(\delta_{\text {iij }}\right)$. Its values above 0.60 are considered acceptable and good above 0.70 (Bagozzi and Yi, 1988; Perreira et al., 2018). To establish convergent validity on the construct level, we calculated average variance extracted (AVE) of the constructs, which is considered acceptable above the threshold of 0.50 (Hair et al., 2014). It was calculated as follows: AVE $=\left(\Sigma\left|\lambda_{\mathrm{i}}{ }^{2}\right|\right) / \mathrm{N}$ ), where $\lambda_{\mathrm{i}}{ }^{2}$ indicates the squared factor loadings, and $N$ indicates the number of indicators. Moreover, to detect any potential problems regarding discriminant validity, we used Heterotrait-monotrait (HTMT) ratio analysis, which indicates discriminant validity issues when HTMT ratios are higher than 0.90 (Henseler et al., 2015). Finally, we estimated the variance inflation factor (VIF) for the predictor, mediator and moderator to detect potential issues of multicollinearity. The values of VIF indicate no multicollinearity below the threshold of 5 (Hair et al., 2018).

Within R 4.0.5 (R Core Team, 2020), the tidyverse package (Version 1.3.0.; Wickham et al., 2019) was used for data transformation, the cfa function of the lavaan package (Version 0.6-8; Rosseel, 2012) for calculating the omega composite reliability indices, the sem function of the lavaan package (Version 0.6-8; Rosseel, 2012) and indProd function of the semTools package (Version 0.5-4; Jorgensen et al., 2021) were used for conducting moderated mediation analysis. The data and analysis code can be found on the project's OSF page: https://osf.io/aw2kg/?view_only= a654da486f67403f8c35a88d1f3a432c (blinded for review).

\section{Coworkers' training participation}




\section{EJTD \\ 47,10}

Variables/

company

\begin{tabular}{llllllllllllllll} 
codes & 01 & 02 & 03 & 04 & 05 & 06 & 07 & 08 & 09 & 10 & 11 & 12 & 13 & 14 & Total \\
\hline$N$ & 149 & 14 & 75 & 101 & 49 & 7 & 59 & 3 & 29 & 57 & 21 & 34 & 54 & 36 & 688
\end{tabular}

Gender

$\begin{array}{llllllllllllllll}\text { (Female) } & 23 \% & 43 \% & 52 \% & 65 \% & 73 \% & 57 \% & 58 \% & 100 \% & 48 \% & 63 \% & 67 \% & 32 \% & 57 \% & 72 \% & 52 \%\end{array}$

Mean age

(SD)

Role

$\begin{array}{llllllllllllllll}\text { (manager) } & 41 \% & 21 \% & 33 \% & 43 \% & 10 \% & 86 \% & 42 \% & 33 \% & 93 \% & 39 \% & 48 \% & 71 \% & 37 \% & 36 \% & 41 \%\end{array}$

Mean time

lag (SD)

$57(29) 42(24) 46(23) 72(31) 46(20) 72(23) 44(25) 25(12) 60(20) 59(40) 50(18) 31(15) 32(21) \quad 35(15) 52(29)$

Coworkers'

participation

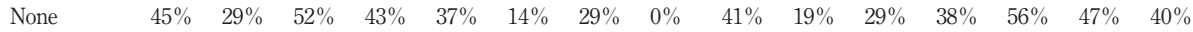

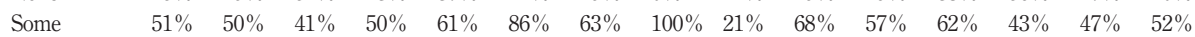

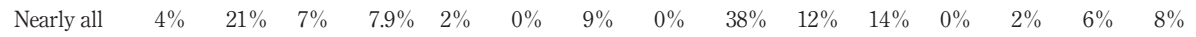

$\begin{array}{llllllllllllllll}\text { Mean peer } & 3.1 & 3.7 & 3.0 & 3.4 & 2.8 & 3.7 & 4.6 & 4.1 & 4.1 & 3.3 & 3.8 & 3.1 & 2.9 & 3.0 & 3.3\end{array}$

$\begin{array}{llllllllllllllll}\text { support (SD) } & (1.4) & (1.8) & (1.6) & (1.5) & (1.2) & (1.5) & (1.8) & (1.4) & (1.5) & (1.4) & (1.3) & \text { (1.7) } & \text { (1.4) } & \text { (1.5) } & \text { (1.6) }\end{array}$

$\begin{array}{llllllllllllllll}\text { Mean mot. } & 5.1 & 5.3 & 5.0 & 4.7 & 5.0 & 6.3 & 5.6 & 5.1 & 5.5 & 5.2 & 4.8 & 4.7 & 5.1 & 5.3 & 5.1\end{array}$

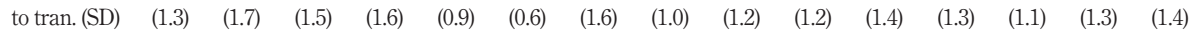

Table A1.

$\begin{array}{llllllllllllllll}\text { Mean train. } & 4.9 & 5.1 & 4.8 & 4.9 & 5.1 & 6.1 & 5.4 & 5.9 & 5.3 & 4.9 & 5.1 & 4.8 & 5.1 & 5.0 & 5.0\end{array}$

Descriptive statistics

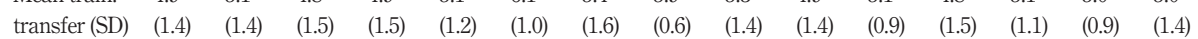

by participating companies

Notes: The table shows the descriptive statistics (means of continuous variables and frequencies of categorical variables) by companies. Time lag = time lag between training and data collection (in days); mot. to tran. = motivation to transfer; and train. transfer = training transfer

\begin{tabular}{lccc}
\hline Variables & PS & MTT & TT \\
\hline Peer support (PS) & - & & \\
Motivation to transfer (MTT) & 0.447 & - & \\
Perceived training transfer (TT) & 0.487 & 0.799 & -
\end{tabular}

Table A2.

Heterotraitmonotrait ratio of correlations
Notes: Entries larger than 1 suggest discriminant validity problems; entries lower than 0.90 indicate sufficient discriminant validity between associated constructs 


\section{References}

Bagozzi, R.P. and Yi, Y. (1988), "On the evaluation of structural equation models", Journal of the Academy of Marketing Science, Vol. 16 No. 1, pp. 74-94, available at: http://dx.doi.org/10.1007/ BF02723327.

Cheung, G.W. and Lau, R.S. (2017), "Accuracy of parameter estimates and confidence intervals in moderated mediation models: a comparison of regression and latent moderated structural equations", Organizational Research Methods, Vol. 20 No. 4, pp. 746-769, available at: https://doi. org/10.1177/1094428115595869

Comrey, A.L. and Lee, H.B. (1992), A First Course in Factor Analysis, Psychology Press, New York, NY.

Cortina, J.M., Markell-Goldstein, H.M., Green, J.P. and Chang, Y. (2021), "How are we testing interactions in latent variable models? Surging forward or fighting shy?", Organizational Research Methods, Vol. 24 No. 1, pp. 26-54, available at: https://doi.org/10.1177/ 1094428119872531

Finkel, S.E. (1995), Causal Analysis with Panel Data. SAGE University Paper Series on Quantitative Applications in the Social Sciences (Vol. 105), Sage Publications, Beverly Hills, CA.

Hair, J.F., Black, W.C., Babin, B.J. and Anderson, R.E. (2018), Multivariate Data Analysis, 8th ed., Cengage, Andover, Hampshire.

Hair, J., Hult, G.T.M., Ringle, C. and Sarstedt, M. (2017), A Primer on Partial Least Squares Structural Equation Modeling (PLS-SEM), Sage, Los Angeles, CA.

Henseler, J., Ringle, C. and Sarstedt, M. (2015), "A new criterion for assessing discriminant validity in variance-based structural equation modeling”, Journal of the Academy of Marketing Science, Vol, 43 No. 1, pp. 115-135, available at: https://doi.org/10.1007/s11747-014-0403-8

Hu, L. and Bentler, P., M. (1999), "Cutoff criteria for fit indexes in covariance structure analysis: Conventional criteria versus new alternatives", Structural Equation Modeling: A Multidisciplinary Journal, Vol. 6 No. 1, pp. 1-55, available at: https://doi.org/10.1080/10705519909540118

Jorgensen, T.D. Pornprasertmanit, S. Schoemann, A.M. and Rosseel, Y. (2021), "semTools: Useful tools for structural equation modeling [computer software manual], available at", https://CRAN.Rproject.org/package $=$ semTools

Kenny, D.A. and Judd, C.M. (1984), "Estimating the nonlinear and interactive effects of latent variables", Psychological Bulletin, Vol. 96 No. 1, pp. 201available at: https://doi.org/10.1037/00332909.96.1.201

Kolbe, L. and Jorgensen, T.D. (2018), "Using product indicators in restricted factor analysis models to detect nonuniform measurement bias", In Wiberg, M., Culpepper, S. A., Janssen, R., González, J. and Molenaar, D. (Eds), Quantitative Psychology: The 82nd Annual Meeting of the Psychometric Society, Zurich, Switzerland, Springer, New York, NY, pp. 235-245, available at: https://doi.org/ 10.1007/978-3-319-77249-3_20

Kolbe, L. and Jorgensen, T.D. (2019), "Using restricted factor analysis to select anchor items and detect differential item functioning”, Behavior Research Methods, Vol. 51 No. 1, pp. 138-151. https://doi. org/10.3758/s13428-018-1151-3

Kolbe, L., Jorgensen, T.D. and Molenaar, D. (2020), "The impact of unmodeled heteroskedasticity on assessing measurement invariance in single-group models", Structural Equation Modeling: A Multidisciplinary Journal, Vol. 28 No. 1, p. 17, available at: https://doi.org/10.1080/ 10705511.2020.1766357

Lin, G.-C., Wen, Z., Marsh, H.W. and Lin, H.-S. (2010), "Structural equation models of latent interactions: Clarification of orthogonalizing and double-mean-centering strategies", Structural Equation Modeling: A Multidisciplinary Journal, Vol. 17 No. 3, pp. 374-391. https://doi.org/10.1080/ 10705511.2010.488999

Marsh, H.W., Hau, K.-T., and Grayson, D. (2005), "Goodness of fit in structural equation models”, In McArdle, J. J. and Maydeu-Olivares, A. (Eds), Multivariate Applications Book Series.

Coworkers' training participation 
EJTD 47,10

Contemporary Psychometrics: A Festschrift for Roderick, in McDonald, P. (Ed.), Lawrence Erlbaum Associates Publishers, pp. 275-340.

McDonald, R.P. (1970), "The theoretical foundations of principal factor analysis, canonical factor analysis, and alpha factor analysis", British Journal of Mathematical and Statistical Psychology, Vol. 23 No. 1, pp. 1-21, availabLe at: https://doi.org/10.1111/j.2044-8317.1970.tb00432.x

Morin, A.J.S., Myers, N.D., and Lee, S. (2020), "Modern factor analytic techniques: Bifactor models, exploratory structural equation modeling (ESEM) and bifactor-ESEM", In Tenenbaum, G. and Eklund, R.C. (Eds), Handbook of Sport Psychology, 4th ed., Wiley

Muthén, L.K. and Muthén, B.O. (2012), "Mplus user's guide, Computer Software Manual], 7th ed., Muthén and Muthén, Los Angeles, CA.

Perreira, T.A., Morin, A.J.S., Hebert, M., Gillet, N., Houle, S.A. and Berta, W. (2018), "The short form of the workplace affective commitment multidimensional questionnaire (WACMQ-S): a bifactorESEM approach among healthcare professionals", Journal of Vocational Behavior, Vol. 106, pp. 62-83, available at: https://doi.org/10.1016/j.jvb.2017.12.004

Core Team, R. (2020), "R: a language and environment for statistical computing", R Foundation for Statistical Computing, Vienna, available at: www.R-project.org/

Rosseel, Y. (2012), "Lavaan: an R package for structural equation modeling”, Journal of Statistical Software, Vol. 48 No. 2, available at: https://doi.org/10.18637/jss.v048.i02

Wickham, H., Averick, M., Bryan, J., Chang, W., McGowan, L., François, R., Grolemund, G., Hayes, A., Henry, L., Hester, J., Kuhn, M., Pedersen, T., Miller, E., Bache, S., Müller, K., Ooms, J., Robinson, D., Seidel, D., Spinu, V., ... Yutani, H. (2019), "Welcome to the tidyverse", Journal of Open Source Software, Vol. 4 No. 43, pp. 1686, available at: https://doi.org/10.21105/joss.01686

Yzerbyt, V., Muller, D., Batailler, C. and Judd, C.M. (2018), "New recommendations for testing indirect effects in mediational models: the need to report and test component paths", Journal of Personality and Social Psychology, Vol. 115 No. 6, pp. 929-943, available at: http://dx.doi.org/ 10.1037/pspa0000132

\section{Corresponding author}

Janos Salamon can be contacted at: salamon.jon@gmail.com

For instructions on how to order reprints of this article, please visit our website: 